BULLETIN Bulletin hispanique

HISPANIQUE Université Michel de Montaigne Bordeaux

$120-2 \mid 2018$

Varia

\title{
La recepción de Lewis Carroll en las letras españolas desde los años setenta
}

\author{
el caso de Leopoldo María Panero
}

La réception de Lewis Carroll dans les lettres espagnoles depuis les années 70 : le cas de Leopoldo María Panero

How Lewis Caroll was seen in the Spanish literary world since the '70: the case of Leopoldo María Panero

\section{Virginia Trueba Mira}

\section{OpenEdition}

Journals

Edición electrónica

URL: https://journals.openedition.org/bulletinhispanique/7281

DOI: 10.4000/bulletinhispanique.7281

ISSN: 1775-3821

Editor

Presses universitaires de Bordeaux

Edición impresa

Fecha de publicación: 10 diciembre 2018

Paginación: 679-694

ISBN: 979-10-300-0337-6

ISSN: 0007-4640

Referencia electrónica

Virginia Trueba Mira, «La recepción de Lewis Carroll en las letras españolas desde los años setenta», Bulletin hispanique [En línea], 120-2 | 2018, Publicado el 02 enero 2022, consultado el 07 enero 2022. URL: http://journals.openedition.org/bulletinhispanique/7281 ; DOI: https://doi.org/10.4000/ bulletinhispanique.7281 


\title{
La recepción de Lewis Carroll en las letras españolas desde los años setenta: el caso de Leopoldo María Panero
}

\author{
Virginia Trueba Mira \\ Universidad de Barcelona
}

La réception de Lewis Carroll dans les lettres espagnoles depuis les années 70 : le cas de Leopoldo María Panero

Cet article analyse la réception de Lewis Carroll dans le domaine des lettres espagnoles du dernier tiers du XX $\mathrm{XX}^{\mathrm{e}}$ siècle et, en particulier, dans les essais et l'œuvre poétique de Leopoldo María Panero. Larticle approfondit les convergences et les divergences entre Panero et l'auteur anglais dans le cadre des idées littéraires de Panero et de sa dette envers la pensée française de l'époque.

Mots-clés: réception littéraire, poésie espagnole contemporaine, Leopoldo María Panero, Lewis Carroll.

Este artículo analiza la recepción de Lewis Carroll en las letras españolas del último tercio del siglo XX y, en concreto, en la obra ensayística y poética de Leopoldo María Panero. El artículo investiga las convergencias y divergencias de Panero con el autor inglés desde el marco del pensamiento literario del propio Panero y de su deuda con el pensamiento francés de la época.

Palabras clave: recepción literaria, poesía española contemporánea, pensamiento literario español, Leopoldo María Panero, Lewis Carroll.

How Lewis Caroll was seen in the Spanish literary world since the '70: the case of Leopoldo María Panero

This article examines how Lewis Carroll was perceived in the Spanish literature in the last third of the 20th century, in both Leopoldo María Panero's essays and poetic works in particular. Our paper investigates convergences as well as differences between Panero and Carroll, using the framework provided by the literary ideas of Panero and his debt toward the French thinking of the time.

Keywords: Literary reception, Contemporary Spanish poetry, Spanish Literary thought, Leopoldo María Panero, Lewis Carroll. 
Encauzar es necesario. Todo el trabajo de lindes y de acequias, de numerología y diccionarios. Pero siempre, al final de tantos loables esfuerzos, surge incontenible

la fuerza de un resto que no tolera cauce alguno

Jorge Riechmann,

Conversaciones entre alquimistas (2007)

\section{ConteXto histórico-LITERARIO}

La obra de Lewis Carroll, como se sabe, ha sido decisiva para la literatura contemporánea. El escritor cubano, Cabrera Infante, afirmaba en febrero de 1971 que Carroll «inventó casi él solo toda la literatura de nuestro siglo [...] Sin Lewis Carroll (y sin Swift, ni Sterne, ni Mallarmé, pero más aún sin Carroll), no habría habido jamás un James Joyce, y sin la lengua bífida del irlandés ni Nabokov, ni Gadda ni Queneau ni Cortázar ni Donald Barthelme ni yo mismo podríamos hablar hoy el mismo lenguaje con un acento diferente» ${ }^{1}$. Pues bien, también en la literatura española de ámbito peninsular hay un nombre que destaca por encima de otros, alguien que leyó muy seriamente a Carroll y lo incorporó de una manera especial a su escritura. Me refiero a Leopoldo María Panero, el cual empieza a escribir sobre Carroll (y sobre Antonin Artaud, al que más tarde me referiré también aquí) en los años setenta, una década importante precisamente en la recepción de Carroll en España.

Es en los años setenta cuando aparecen, por ejemplo, las traducciones decisivas de Jaime de Ojeda para Alianza Editorial de Alicia en el Pais de las Maravillas en 1970 y de Alicia al otro lado del espejo en 1973, acompañadas de dos sustanciosos y excelentes prólogos y de las ilustraciones, por vez primera en España, de John Tenniel. Otras traducciones fueron asimismo las de Alfredo Deańo, El juego de la lógica y otros escritos también para Alianza Editorial en 1972, o las de El paraguas de la rectoría. Cajón de Sastre de Carlos Miguel Sánchez-Rodrigo para Ediciones del Cotal en 1979. En 1972 aparece igualmente La caza del snark en versión ahora ya de Leopoldo María Panero en Ediciones Libertarias, y en 1975 se publican también las versiones panerianas de los textos que integran el volumen, Matemática demente, en edición acompañada de un extenso prólogo que analizaré con detenimiento enseguida, ya que resulta de capital importancia para el propósito del presente trabajo a la hora de mostrar la convergencia y divergencia de Panero con Carroll. Por su parte, José Luis Giménez Frontín publica en 1974, con prólogo de Brassaï, el libro de las fotografías de Carroll con el título, Niñas. Esta rápida enumeración no pretende ser exhaustiva en relación a la presencia de Carroll en los años setenta, es tan solo un botón de muestra del interés que Carroll suscitaba en España en aquellos años.

1. Citado en Jaime de Ojeda, «Prólogo» a Lewis Carroll, Alicia al otro lado del espejo, prólogo, edición y traducción de Jaime de Ojeda (Carroll 1973: 10). 
Prescindiendo ahora de la proyección internacional que tuvo entonces la obra de Carroll en Estados Unidos y en Europa gracias a las diversas tentativas conceptuales, psicodélicas o del mundo pop, provenientes del cine, las artes plásticas o de la propia literatura, este interés por Carroll en Espańa tiene que ver probablemente con una situación social y política necesitada de la extra-vagancia de los textos del autor inglés. La anécdota que cuenta el mismo Panero en cierta ocasión es bien significativa al respecto : explica Panero que tras someterle a la terapia de los electroschoks, Juan José López Ibor, el conocido psiquiatra español del largo franquismo, le ponía una imagen de Santa Teresa de Jesús en la mesilla. No es difícil establecer el paralelismo entre la lógica desquiciada de Carroll y la lógica desquiciada de la situación espańola, no lejana por otro lado, aunque de distinto modo, a la de aquella Inglaterra honorable de Carroll, de sospechosos y sórdidos mundos ocultos sin embargo, como el de Jack el Destripador, a quien se ha llegado a identificar con numerosos personajes reales del período victoriano, incluido, por cierto, con el mismo Carroll, como ocurre en la obra de Richard Wallace, Jack the Ripper: Light-Hearted Friend, Gemini Press, 1996 (Praga 2015). En este aspecto, Carroll venía a mostrar a los españoles cómo se podía dar la vuelta a las cosas, no tanto en el sentido de su in-versión (como en el famoso poema de José Agustín Goytisolo, «Érase una vez», musicado después por el cantautor Paco Ibánez, que hablaba de un «lobito bueno», de una «bruja hermosa» o de un "pirata honrado»), sino en el de su per-versión, la de aquel "galimatías» o «galimatazo» del poema de Carroll, "Jabberwocky» (tal como tradujo el título Jaime de Ojeda), un poema donde el solo concepto de identidad (sea esta cual sea) hace reír, pues resulta definitivamente imposible.

Desde el punto de vista literario, los setenta son años en España de agotamiento de las poéticas llamadas «comprometidas», las cuales habían atravesado toda la dictadura, primero en versiones más urgentes y temáticas (Gabriel Celaya, Victoriano Crémer o Ángela Figuera), luego en versiones más detenidas y autoconscientes (Jaime Gil de Biedma, Ángel González o José Angel Valente). De ahí que surjan en los setenta poéticas nuevas que, sin ignorar por completo lo anterior, niegan con toda radicalidad que las palabras deban estar re-ligadas (re-ligiosamente) a un significado, incluido el político. Su "compromiso» (que también lo hubo) pasa ahora por la denuncia de una lengua que, como había dicho Roland Barthes, es siempre fascista, no tanto porque impida decir sino porque obliga a decir (en cuanto hablo, soy hablado, algo o alguien habla por mí), lo que en el caso español ya a esas alturas adquiría una particular resonancia. Son poéticas que durarán hasta que los nuevos poetas, los integrantes de la denominada "poesía de la experiencia», ya en los años ochenta, es decir, en tiempos de democracia, consideren que las cosas deben re-ligarse de nuevo a sus sentidos. La lección de Carroll, sin embargo, no desaparece como demuestra que a final de los noventa otras voces, sin formar ahora grupo homogéneo, la reclamen, ya no solo para desestabilizar los cimientos de la dictadura franquista sino también los de las dictaduras de los mercados, no ajenos, no obstante, al último franquismo. 
La recepción de Carroll desde los años setenta hasta hoy permite, por lo tanto, construir lo que me interesa destacar también en este trabajo: un cierto relato de la sensibilidad poético-política española que tiene, eso sí, uno de sus epicentros en la escritura de Leopoldo María Panero, esa especie de piel roja de la reserva hispánica, donde los tambores han gritado la muerte de Sitting Bull sin esperar respuesta, como él mismo escribió en el poema «Deseo de ser piel roja» de Asi se fundó Carnaby Street (1970) (Panero 2004: 64).

\section{LA DISOLVENCIA DEL SENTIDO EN LEOPOLDO MARÍA PANERO}

Con motivo de un texto de Vicente Molina Foix, en un artículo de 1974 hacía Panero la siguiente declaración en la que quisiera detenerme ahora: «No hay identidad alguna [ni obra, ni tema, ni autor] en la que un lector pueda hallar su espejo y regodearse: no hay nada que leer» (Panero 2014: 484, Artaud 1971: 80) ${ }^{2}$. Estamos en el núcleo de la poética paneriana, que conviene tener presente para comprender después su proximidad a Carroll. Panero está denunciando aquí todo un orden social y el pensamiento que lo sustenta.

«No hay nada que leer» quiere decir que la vida está ausente aquí, en ese texto. Es una negación de la vida, y esto es importante subrayarlo aún a riesgo de ser excesivamente didáctico, en un sentido activo, en tanto es la negación de la negación, la negación del relato represivo que impone el orden social. «Nada que leer» quiere decir que la razón no ha actuado con anterioridad en la dirección de construir un referente único para las palabras, haciéndolas aparentemente portadoras de una verdad con la que se construirá aquel relato. Y es ahí donde Panero precisamente resiste, en una postura que tiene muy poco de intelectual y mucho de vital (con su dosis de angustia incluida). «Interminable red de engaños / llamada Razón, llamada Pensamiento", dice también en un poema de Teoría $(1973)^{3}$. Panero milita desde el principio contra la vergüenza, entiende, de un lenguaje doblegado a una razón re-presentativa, que pretende re-presentarnos, una razón que irracionalmente no mueve ficha, empeñada siempre en el mismo concepto de identidad y de verdad. Re-presentación y represión se diría que en Panero son sinónimos. Panero está lejos de ahí, como si remontara el curso de todos los relatos para alcanzar y enfrentarse a lo anterior a todo relato (a todo contrato social), a aquello que es inexpiable e intratable, que nos iguala sin igualarnos, que nos asemeja a través de la diferencia insalvable que somos cada uno de nosotros. Un horror, si se quiere, ese horror que el orden burgués enmascara como un simple error, como cuando convierte, por ejemplo, la locura en una enfermedad mental ${ }^{4}$. Lo que nos anuncia esta frase, «no hay

2. Leopoldo María Panero, «De Panero a Vilumara». La frase de Panero suena como un eco de aquella otra de Antonin Artaud en la célebre Carta a la vidente: «Y ya os lo he dicho; nada de obras, nada de lengua, nada de palabra, nada de mente. Nada. Nada más que un bello PesaNervios».

3. Leopoldo María Panero, «Vanitas Vanitatum» (2004: 132).

4. Sobre este horror convertido en error, ver Miguel Morey (2014: 68). 
nada que leer» es ese horror, del que Panero extrae, en realidad, toda su energía creadora. "Donde tiembla mi voz, / comienza el poema», dice también en unos versos de Guarida de un animal que no existe $(1998)^{5}$. Es esa voz que se resiste a hablar con autoridad, con propiedad (¿de qué puede ser propietaria una voz?), la voz de ese simulacro que somos ya, porque perdimos hace mucho tiempo la ilusión de la semejanza con cualquier original. Así lo entiende Panero, lector empedernido de Deleuze aquí.

Casi no hace falta decir que la dimensión política de ese «no hay nada que leer» es primordial, y ello porque el poder, tal como aparece en la escritura de Panero, no puede no leer, porque el poder trabaja siempre sobre un sentido, e incluso sobre un contrasentido, pero pierde pie ante lo disolvente, como ha estudiado bien John Holloway en un libro titulado Cambiar el mundo sin tomar el poder. El significado de la revolución hoy (Holloway 2002: 20) ${ }^{6}$, que trata sobre nuestro mundo transtornado y sobre la necesidad de un grito que sea $a$ un tiempo de horror-y-esperanza. La escritura paneriana trabaja en esa dirección, en la disolución de la mentira del relato representativo, al modo del cine de Godard, el cineasta de la época, y su montaje diferencial, no dialéctico, que insiste también en la disolvencia de lo identitario. Con motivo precisamente del cine de Godard, Ana María Moix, una escritora muy cercana a Panero y tan mal leída como Panero, o mejor, no leída, respondía en una carta de agosto de 1966 a una muy crítica y muy poco godardiana Rosa Chacel con estas palabras: «nunca adivino qué plano va a venir después de otro» (Chacel - Moix 1998: 166). De eso se trata, de que el hilo se pierda y de que de ese modo pueda tener lugar una práctica no política de la política, es decir, la Gran Política, dirá Panero con Nietzsche, o sea, la Revolución.

Puede entenderse entonces la proximidad de Panero a un autor como Carroll, en el que las palabras están también desasidas de sus sentidos, de ahí que Alicia tenga que preguntar todo el rato, ¿en qué sentido, en qué sentido?, pues no está claro ya en qué sentido se están empleando. Los significantes flotantes, en movimiento, de Carroll son también una respuesta a los significantes despóticos del poder y a la convicción de que el lenguaje nos dice, nos representa. También Carroll nos dice que aquello que las palabras ciertamente significan, si se les resta la intencionalidad del hablante, se parecen mucho a nada.

Vayamos ya a la presencia explícita de Carroll en Panero, la cual atraviesa toda su escritura. Carroll está en primer término en sus propios versos a través, por ejemplo, del uso de palabras-valijas o de palabras directamente inventadas?

5. Leopoldo María Panero, «Y(ETA)», Guarida de un animal que no existe (2004: 537).

6. Se ha referido a este libro un autor que, a finales de siglo, creará junto a otros escritores españoles el colectivo llamado precisamente Alicia Bajo Cero, al que me referiré más adelante. Se trata de Antonio Méndez Rubio (2008: 195-196).

7. Es el caso, entre otros, del juego con los significantes de El canto del Llanero solitario, que es la segunda parte del libro Teoría (1973), donde aparece la palabra-valija «hagoaliciaenelespejojoven» o la invención de «verf» o «barrabum» (en Leopoldo María Panero, El canto del Llanero solitario, Teoría, 2004: 85-86). 
No es, sin embargo, esa presencia la que me interesa subrayar ahora, sino la que se encuentra en los textos periodísticos que Panero escribió, que no fueron pocos $^{8}$, en los que es muy frecuente la alusión a dos escenas de Alicia... que podrían resumir, en realidad, los dos frentes abiertos, complementarios, de la escritura paneriana: la primera escena es la de la merienda de locos, en la que siempre es la hora de tomar el té, donde falta, por tanto, la situación, la circunstancia, es decir, el otro, como ocurre en el capitalismo, entiende Panero, en el que «siempre es la misma luna y la misma mañana, el mismo veneno y la misma CIA, el mismo manicomio y la misma muerte, lejos de la verdad, de nuestra única y posible verdad, que son los carruajes vacíos en el crepúsculo, moviéndose en dirección al Salón de los espejos»". La segunda escena es la de la tienda de la oveja, donde contrariamente a la merienda de locos, todo está permanentemente en movimiento, como el significante, siempre flotante, que impide el sentido fijo y libera de la responsabilidad para con una única verdad $^{10}$. Ahí, en la resistencia al sentido único y en la defensa de un sentido siempre desplazado, retardado, imposible, se juega toda la escritura paneriana.

Por otro lado, Carroll está presente también en las particulares traducciones de Panero. Como dije al principio del trabajo, Panero traduce, entre otros, el famoso poema de Carroll, La caza del snark, que ve la luz en 1972. También en 1975 se editan los textos del volumen Matemática demente, cuyo prólogo contiene una precisa síntesis del pensamiento poético de Panero en convergencia divergente con la de Carroll. Es el texto que quiero tomar como referente a partir de ahora para continuar ahondando en el sentido de la recepción de Carroll en Panero ${ }^{11}$. Vale la pena, sin embargo, mencionar antes de seguir en esa dirección el parecido que guarda la estructura de este prólogo con la superficie por donde se mueve Alicia. El texto de Panero está lleno de agujeros por los que caemos y de los que nunca regresamos. Se trata de los paréntesis, que no tienen aquí, como era de esperar, ninguna función aclaratoria sino más bien todo lo contrario: se abren sin cerrarse, se ausentan dejando su huella, se generan unos dentro de los otros, se deforman transformándose en otra cosa, en dos puntos por ejemplo, etc. Imposible transitar aquí en línea recta, imposible la lectura convencional. En este aspecto, este prólogo es un texto sobre Carroll pero también un texto desde Carroll, desde su alteración de la lógica habitual.

Vayamos ya al contenido del prólogo.

8. Recogidos ahora en Prosas encontradas, en edición de Fernando Antón (Panero: 2014).

9. Leopoldo María Panero, «La noción de pecado como certidumbre del otro», (2014: 471).

10. Leopoldo María Panero, «Sobrevolando a Deleuze», (2014: 188).

11. Leopoldo María Panero, «Sobre la traducción», prólogo a Lewis Carroll, edición, traducción y prólogo de Leopoldo María Panero, Matemática demente, (1975). El poema La caza del Snark y la parte de Matemática demente escrita en verso (Un grito repetido tres veces: ¡Fuera del principio poético.), pueden leerse ahora en el volumen de Túa Blesa donde se recogen las traducciones poéticas de Panero (2011). 


\section{DE CARROLL A ARTAUD}

Una parte importante de ese prólogo está dedicado a la traducción, no en vano el prólogo lleva por título precisamente, «Sobre la traducción». La traducción ha sido siempre elemento decisivo o central del pensamiento poético de Panero, aunque en este caso también es cierto que la insistencia en proteger su propia traducción responde a la necesidad que tiene Panero de defenderse de la imputación (policíaca, siniestra, resentida, sostendrá) de los críticos y traductores puros por sus anteriores traducciones impuras y perversas, como él mismo las denomina. Es importante entender esta per-versión para entender, a su vez, la escritura paneriana, ya que su teoría de la traducción, lejos de ser un elemento menor, es esencial, como digo, en el conjunto de su pensamiento poético.

Partamos de lo principal. Para Panero no existe el concepto de texto original, identitario, completo, en el sentido de poseedor de su propio y único sentido. La palabra «origen», como diría Terry Eagleton, es para Panero propia de una «teología desplazada» (Eagleton 2007), es una palabra cómoda para cierta lógica pero ridícula para un pensamiento que se quiere de-generado, sin padres, antiedípico, radicalmente huérfano. Para Panero en todo texto hay siempre un resto diferente, algo queda siempre por decir en todo texto, algo está siempre tácito, en suspenso, suspendido quizás, gracias a lo cual precisamente ese texto puede seguir desplegándose, interpretándose, traduciéndose... en otros textos que, por su parte, tampoco serán nunca textos completos y cuyos silencios se desplegarán en otros textos que, a su vez... Son numerosos los versos de Panero en los que se hace mención expresa de esa diferencia irreductible, aquí la lectura de Deleuze es primordial, en que consiste el sentido. En un poema, «Parábola del diccionario», del libro Epílogo (1994) escribe Panero lo siguiente: «Una palabra reenvía a otra palabra, un sentido a / otro sentido: el sentido se extiende como la / cabellera de una dama rubia, en la orilla / tocando el mar y los barcos / [...] / Pero volviendo a la pregunta sobre el sentido, / éste, como el Tao supo, escapa al decir, esto es que el / sentido no es figura del discurso" (Panero 2004 : 459). El sentido no se dice, no puede decirse, no es figura del discurso. Por eso un poema corre siempre el riesgo de no tener sentido y no sería nada sin ese riesgo. Esta es una afirmación conocida de Jacques Derrida que, como un leiv motiv, recorre por su parte toda la escritura paneriana, lo mismo que la referencia a aquellas dos escenas de la Alicia de Carroll, la de la merienda de locos y la de la tienda de la oveja. Obsesiones de un poeta que, como se dijo, resiste ahí, en la palabra no representativa. La condición entonces de toda escritura será ser re-escritura. Lo decía también el eslogan del film $2 \times 50$ ans de cinéma français (1995) de Jean-Luc Godard: «No / copy / right». Por otra parte, si no hay texto original, no hace falta insistir mucho en que tampoco hay, en consecuencia, texto secundario, o sub-alterno o degradado, respecto de ese supuesto texto original, que es como se consideró tradicionalmente al texto traducido. Todo es un desplegarse, en última instancia, del mismo texto, de su 
diferencia, de su hablar sin decir. Lo que hace la traducción es trabajar ahí, en la diferencia, explotándola, lejos de copiar servilmente una supuesta identidad ${ }^{12}$.

Pues bien, de estas convicciones parte Panero para emprender sus traducciones, esos «monstruos» como los llama, monstruos porque tienen que respetar y desplegar lo que el texto no dice. Por eso llama a esas traducciones "per-versiones", porque son versiones que aumentan el texto, en tanto desarrollan o explican eso no dicho de ese texto. El valor que para Panero tienen los textos de Carroll en concreto radica precisamente en los silencios deliberados con que trabajan, con que juegan. Y Panero se aprovecha de ello hasta el límite, o mejor, hasta fuera ya de todo límite. Panero crea a sus anchas a partir de Carroll, recorta, retoca, reduce. Un ejemplo extremo es La caza del snark, "la per-versión más perversa de todas las de Panero», como la ha denominado Túa Blesa (1995: 19), en la que Panero transforma incluso la voz narradora del hombre en la de una niña. También los textos de Matemática demente pertenecen a las perversiones panerianas. En realidad, las traducciones de los textos de Lewis Carroll han sido siempre especialmente complejas y han obligado en ocasiones a un ejercicio de imaginación, no tan lejano tal vez al que practica Panero. Aún sin llegar al extremo de este último, Jaime de Ojeda, en el prólogo a su edición de Alicia en el País de las Maravillas, afirmaba que «toda traducción de Alicia ha de estar cargada de un alto grado de impresiones subjetivas" (Carroll 1970: 25). Y en Alicia al otro lado del espejo hacía la siguiente declaración: «estoy tan seguro de mi traducción como lo estoy de mi infidelidad científica y de mi traición al clásico carrolliano» (Carroll 1973: 26). Salvando, como digo, la distancia con Panero, también Jaime de Ojeda, como Panero, considerará al traductor una figura cercana a la del poeta, en tanto ambos son capaces de recuperar el «espíritu oculto de los idiomas» que es en los dos casos el espíritu de la infancia, de esa infancia donde el logos aún no ha colonizado la realidad de los cuerpos ${ }^{13}$.

Si seguimos ahondando en el pensamiento poético que Panero despliega en este prólogo no podremos eludir algo fundamental: la presencia que tiene en él precisamente la infancia, pero también la locura, sus lenguajes. Infancia y locura resultan imprescindibles en todo acercamiento al pensamiento paneriano. Panero parte de la convicción de que Alicia en el Pais de las Maravillas es el texto

12. No son extraños los casos en que incluso la traducción supera al original, como explicaba en cierta ocasión Georges Steiner, quien ponía el ejemplo de los sonetos de Louise Labé, la poeta del XVI, que ya no se leen en francés sino sobre todo en la versión alemana de Rainer María Rilke (George Steiner, 1998: 305).

13. Es importante la reflexión de Jaime de Ojeda en relación a la poesía. Sostiene Jaime de Ojeda del poema "Jabberwocky» que las palabras inventadas están tan bien hechas que suenan a palabras verdaderas, «evocan auténticos significados -escribe- que hasta entonces no habían tenido expresión y que Carroll acrisola en términos que tienen la solera de un largo uso. Tanto es así que algunas palabras inventadas por Carroll en el "Jabberwocky", y más tarde en La caza del Snark, se han introducido en el lenguaje corriente y figuran hoy en los diccionarios como si tal cosa, sin mencionar incluso su reciente origen en la obra de Carroll» (Jaime de Ojeda en Lewis Carroll, Alicia al otro lado del espejo, 1973: 190). 
esquizofrénico por excelencia debido a su juego con el sentido de las palabras, y por eso no es gratuito, entiende Panero, que su autor lo escribiera (o lo hablara, recordemos el origen oral del relato de Carroll) para una nińa (también la infancia es para Panero esquizofrénica). Panero no dice nunca, como Carroll, que quiere escribir para niños, pero la infancia recorre toda su escritura desde el principio, algo que merecería, sin duda, un estudio a fondo un día. La infancia para Panero es la anarquía, es, lacanianamente, el momento anterior al estado del espejo, en que aún no ha aparecido ese yo «que marca al hombre como una res» (en Carroll 1975: 32) y lo aísla para siempre, ese yo que luego se convierte en alguien, en un autor por ejemplo, con autoridad sobre su texto (o en un padre con autoridad sobre su hijo). Hay siempre en Panero una resistencia a la falacia autorial y un convencimiento de la necesaria despersonalización de la escritura. El autor debe morir, pues no es él en realidad el que habla sino el mismo lenguaje. «No hay comunicación porque hay yo», denuncia Panero (en Carroll 1975: 24). Eliminado el yo, tal vez podríamos volver a estar juntos, ya que eliminado el yo, regresa el otro, pero ya no como otro sino como próximo, y próximo paradójicamente por su propia diferencia.

El nacimiento del yo supone también para Panero -Lacan sigue estando presente aquí- el nacimiento del cuerpo. El cuerpo es precisamente con el que se viste a ese $y o$, con el que se le territorializa y se le convierte en organismo disciplinado que puede controlarse. De ahí también la rotundidad de la declaración de Panero en el prólogo: «Hace falta no tener cuerpo para estar desnudo" (en Carroll 1975: 33). Lo interesante entonces del niño, como del loco, es que resulta ajeno a la estructuración del sujeto, puesto que habla, ya no desde el logos sino desde su no-cuerpo, por eso puede no decir, salirse de las casillas estables del lenguaje -en latín, recuerda Panero, «in-fans» significa un «sin palabra» (en Carroll 1975: 32)-. Por lo tanto, regresar al niño en Panero es regresar a esa palabra que no dice, que no re-presenta, palabra vacía y por ello verdaderamente plena. Frente a esa palabra, se encuentra la del homo normalis, aquella que se empeńa en significar, la del sentido supuestamente común, siempre indigesto, precisamente por ser tan digestivo. Ese sentido común es el que Panero no puede tragar, su boca se lo impide, es el que vomita allá donde va (bares, universidades, manicomios, cárceles...), porque, como lamenta en un verso, «no hay infancia en este país desierto» ${ }^{14}$.

Pues bien, precisamente la palabra de Carroll para Panero es también aquella que hace callar la lógica del lenguaje, la que se ríe de esa lógica. De hecho, la risa (la del humor, no la de la ironía) ocupa un espacio amplio en el prólogo a Matemática demente. La risa es la que pre-siente lo que aquí está en juego, lo incierto de toda certidumbre, y por eso en última instancia la risa es también el «fracaso de la represión» (en Carroll 1975: 37). La reflexión de Panero sigue aquí de cerca la de Gilles Deleuze en Lógica del sentido. Panero diferencia la risa del humor (la del estoicismo, el zen o cierto pensamiento contemporáneo) de la

14. Leopoldo María Panero, «Pavane pour un enfant défunt», Narciso en el acorde último de las flautas (2004: 145). 
risa de la ironía. El humor, sostiene Panero, trabaja en la grieta que hay en todo texto, la ironía contrariamente trabaja en la confirmación ("es risa constipada», escribe). El humor es disyunción y diferencia, la ironía es conjunción. El humor es sentido y sin-sentido al mismo tiempo, la ironía siempre busca reinstaurar un significado a través del sin-sentido. En el humor no hay alturas que valgan, el humor actúa como venganza hacia el padre, es un movimiento de superficie, mientras que la ironía surge cuando las ideas no están conformes con las cosas, crea un movimiento de arriba a abajo y supone una dimensión moral. La risa del humor es revolucionaria, se ríe porque se ríe, la ironía es reformista, es la risa de las cadenas, sentencia Panero. De lo que se ríe la risa es, en realidad, del «fantoche humano». Una escritora espańola actual, a la que me referiré al final de este trabajo, cuyo apellido es precisamente Liddell (el apellido de la Alicia real a la que, como se sabe, Carroll dedicó su relato), definía lo moderno como la desesperación del mono que jamás deseó llegar a ser hombre. Con eso tiene que ver la risa, con ese hombre, al fin, ridículo en su cuerpo y en su lenguaje ortopédico, empeñado en ser lo que no es, lo que le dicen que tiene que ser (Liddell 2014: 36).

Ahora bien, si Carroll está en Panero desde la perspectiva que acabo de exponer, también lo está Antonin Artaud, esa especie de doble de Panero, que sintió también que la lengua le impedía hablar. Los autorretratos de Artaud y las últimas fotografías de Panero, como se ha advertido muchas veces, se parecen sospechosamente: la misma boca enorme y desdentada, el mismo rostro que pregunta, que nos pregunta, que sale a buscarnos porque ese rostro somos nosotros mismos, como ha visto bien Valeriano Bozal en el caso de Artaud (Bozal 2004: 49). Rostros todos ellos (también los de algunas figuras desfiguradas de Francis Bacon), de trazo imperfecto, torpe, porque se resisten a hacer obra, porque hacen algo más importante: enfrentarnos a lo intratable. Lo interesante, no obstante, es la confluencia de Panero con Artaud precisamente en relación a Carroll, a quien Artaud también tradujo y adaptó. Vayamos a ello.

Artaud, como Panero, encuentra en Carroll a un autor que pone patas arriba la lógica identificativa y especular del signo. En este sentido le interesa Carroll y por eso traduce sus textos. Ahora bien, hay un momento en que Artaud se rebela contra Carroll, contra ese caos carrolliano que le resulta, finalmente, demasiado lógico y demasiado pensado. Aburrido. En realidad, no hay que olvidar que Alicia sale sin heridas de su aventura, al final únicamente despierta de una siesta. La lógica descentrada de Carroll deja todo, entiende Artaud, paradójicamente como estaba. Lo que incomoda a Artaud es el juego semiótico de Carroll, que Carroll trate el lenguaje como una especie de puzzle donde intercambia, altera, invierte las piezas, con la finalidad de advertir sobre la confianza en su sentido único. Artaud encuentra que ahí falta algo: falta el cuerpo. La voz de Carroll es para Artaud fría y distante, es la voz de un pensamiento que juega, no de un cuerpo que vive (desde la impulsividad de la materia, no desde ningún orden social, Artaud 2011: 41). Carroll juega con 
las palabras, entiende Artaud, como si fueran restos, excrementos, juega con ellas como un niño juega con sus heces. Este es precisamente el problema de Carroll para Artaud: su infantilismo. Lejos de las heces carrollianas, en Artaud el lenguaje es un conjunto de haces de energía que discurren a través de un cuerpo sin órganos por el que toda energía debería fluir sin que nada la obstaculice. En Artaud el lenguaje no es ya, por tanto, un espacio compacto de signos sino el conjunto de gritos, alaridos, espasmos con que el cuerpo se pone en contacto con el mundo. Es el terreno del «infrasentido», como lo ha denominado Deleuze, de un «sinsentido» si se quiere, que ya no es el de Carroll o el de la tradición inglesa del «non sense», porque es un «sinsentido» que engulle todo sentido, tanto del lado del significado como del significante. El Ser es «sinsentido» para Artaud, nos recuerda Deleuze, y «tiene dientes» (Deleuze 1989: 107). No es casual en este aspecto que la escritura y el pensamiento de Artaud, como los de Samuel Beckett, dieran un giro hacia el teatro, donde el lenguaje-cuerpo encontró el lugar donde desplegarse, un teatro de la crueldad (contra la palabra y el juicio de Dios) muy cercano a ciertas escenas sacras del teatro antiguo, en las que tampoco había nada que ver, nada que leer, habría dicho Panero. Teatro donde la re-petición es imposible, y por tanto tampoco la identidad, donde es imposible la re-presentación, la re-presión. La consigna artaudiana fue siempre la misma: "Menos palabras y más deseo»: son palabras del mismo Panero en un texto sobre Nietzsche ${ }^{15}$.

Panero se suma en principio al juicio de Artaud sobre Carroll, de quien llega a decir incluso que fue un "cobarde que no se atrevió a vivir su escritura» (en Carroll 1975: 66). En este aspecto, Panero, que hizo de la literatura su propia vida, está también lejos de Carroll. Ahora bien, precisamente porque hizo de la literatura su propia vida, porque nunca abandonó la literatura (la escritura), Panero no tiene posibilidad alguna de alcanzar esa (otra) vida de la que habla Artaud («destruir el lenguaje para alcanzar la vida», había dicho Artaud, 2011: 16). Panero no puede, no quiere, no sabe dejar de escribir, aunque lo que busca en su escritura sea precisamente destruir el lenguaje, callarse. Por ello, Panero se sigue manteniendo en el terreno de la superficie, lejos del «infrasentido» de Artaud, aunque el trabajo en esa superficie no es siempre el mismo que el de Carroll. Panero sigue a veces a Carroll en cuanto a su juego con el léxico, pero creo que el núcleo del juego de Panero es otro: tiene que ver con ese conjunto de voces y ecos (máscaras, disfraces) que constituyen en Panero el único teatro desde el que hablar. Lo que se lee en Panero al final es el mismo lenguaje, sus voces des-medidas: de ahí una escritura llena de citas, de glosas,

15. Leopoldo María Panero, "Contra el libro» (2014: 61). La siguiente reflexión de Deleuze sobre Carroll y Artaud en Lógica del sentido se sitúa muy cerca del sentir de Panero: «No daríamos una página de Artaud por todo Carroll; Artaud es el único que fue de una profundidad absoluta en literatura, y descubrió un cuerpo vital y el lenguaje prodigioso de este cuerpo, a fuerza de sufrimiento, como él dice. Exploraba el infra-sentido, todavía hoy desconocido. Pero Carroll continua siendo el maestro o el agrimensor de las superficies, que se creían tan bien conocidas que ya no eran exploradas, en las que se encuentra sin embargo toda la lógica del sentido» (en Gilles Deleuze, 1989: 109). 
de plagios, es decir, más que nunca una reescritura. Es E. A. Poe, T. S. Eliot, es Guillem de Peitieu (que ya en el siglo XII dijo querer construir un verso sobre absolutamente nada) pero también es Peter Pan, Blancanieves y Campanilla, y son asimismo las voces de las revistas de moda que, fuera de contexto, en el poema, actúan a modo de los ready-made duchampianos, como ha señalado Túa Blesa (1995: 25), etc. Panero no despierta, como Alicia, después de la siesta porque, en realidad, nunca durmió, es el insomne por excelencia, Panero siempre vivió en otro mundo: la literatura. Y de hecho, su obsesión por Mallarmé, un poeta tan distinto en su escritura, probablemente tiene que ver con ello. Lo que Mallarmé encuentra al final de su viaje no es el sentido, sino su propio poema, ese poema que dice "nada». Imposible decir, pero imposible callar: en la bisagra que configura esas dos impotencias se desarrolla toda la escritura de Panero.

\section{INTERRUPCIONES Y CONTINUIDADES EN LA RECEPCIÓN DE CARROLL}

Volviendo ahora al principio de este trabajo, para muchos españoles de los años setenta los textos de Carroll tuvieron el atractivo de poner sobre la mesa los «mitos que animan nuestras palabras», para decirlo con Michel Foucault (2010: 291). En España, uno de esos mitos fue siempre el de la madre patria, que hizo del español en tantos momentos el idioma del imperio hacia Dios. Contra esa madre patria llamada España y contra su idioma escribe Panero algunas de sus frases más incendiarias. "Que Dios perdone mi odio, y lo perdona, / pero tú no, animal hispano, bestia que no perdonas», dice en un poema $^{16}$. A España o a Spanndereta, se refería por su parte Juan Goytisolo (2006) para denunciar el ninguneo a que era sometido Julián Ríos, autor, por cierto, de los relatos de Sombreros para Alicia (1993), con dibujos de Eduardo Arroyo, y Nuevos sombreros para Alicia (2001), textos palimpsésticos donde los haya. Por su parte, Julián Ríos se refería a Goytisolo del siguiente modo en su Album de Babel (1995): «Español: idioma nuestro que está en España. Eso le impide [a Juan Goytisolo] escribir con claridad» (1995: 144-145).

Si Ríos descoloca la lengua española al reescribirla, Goytisolo la torsiona al modo de los laberintos de esas ciudades árabes que tan bien conoce (Marraquesh, Tánger, el país de las maravillas, como lo llama el biógrafo de Panero, Benito Fernández), tan opuestos a los espacios cuadriculados y previsibles del París de Hausmann. Y aunque en África se le manifiesta a Goytisolo el caos como forma de vida, en París lo ha descubierto como forma de pensamiento (Buckley 1996: 92). Laberíntico es precisamente el relato de

16. Leopoldo María Panero, Guarida de un animal que no existe (2004: 531). "Que los pájaros [...] perdonen al animal hispánico por haber destruido el mundo», dice en otro sitio (Leopoldo María Panero, «Acerca del pretendido animal (Espańa, no mates más)», 2014: 455). De «homunculus hispanicus», habla también en un artículo ("Acerca de Jean-Paul Sartre», 2014: 442). 
Paisajes después de la batalla, aparecido en Seix Barral en 1982, descentrado, fragmentario, donde las piezas no acaban de encajar formando unidad, es, en realidad, el homenaje de Goytisolo a la Alicia de Carroll. Lo interesante es tener presente que todos los autores mencionados, y otros muchos, actuaron al modo del viejo topo del que habló Philippe Sollers precisamente en relación a Artaud, un viejo topo cuya actividad no fue tanto minar los cimientos de la sociedad sino revolver su propia tierra (Sollers 1977: 8).

Lo que me interesa destacar ahora es que esta escritura disipadora de mitos pronto empezó a ser desacreditada por los nuevos protagonistas del discurso poético, los poetas de la futura "poesía de la experiencia» como se denominará, que empieza a emerger en los años ochenta, en el contexto de una democracia en la que para muchos parece no haber ya conflictos con los aparatos ideológicos del estado. Tras las radicalidades -Pere Gimferrer dixit- de los años setenta, la poesía de la experiencia busca regresar a un lenguaje realista, que entiende lamentablemente perdido en la historia reciente de la poesía española. Este realismo ha sido objeto de polémica y debate hasta hoy mismo, entre otras cuestiones porque en demasiadas ocasiones los poetas de la experiencia lo vincularon sin más a una estética figurativa. Como se sabe, realismo y figuración son dos conceptos distintos que pueden darse la mano -Edward Hopper- o darse la espalda -Salvador Dalí- y, en este sentido, no siempre los nuevos poetas matizaron su sentido cuando los emplearon juntos. E incluso cuando aparentemente se dan la espalda, como en el caso, por ejemplo, del surrealismo, podría hablarse de realismo desde un cierto punto de vista: es la realidad del sueño en este caso, y de los procesos psíquicos que le son propios, lo que el surrealismo pone en escena. Es por ello por lo que Jenaro Talens puede llamar a Panero "rabiosamente realista ${ }^{17}$ y el mismo Panero haya defendido en infinidad de ocasiones el valor realista de la escritura de Kafka, su valor de verdad, de esa verdad que el capitalismo, cerrado a todo tipo de otredad, no puede nunca decir, la verdad de lo esquizofrénico: «la cucaracha no dibuja ninguna alteridad metafísica, sino que es la realidad más cercana a Gregorio Samsa», a su yo estigmatizado, escribirá Panero ${ }^{18}$. Además del realismo y la figuración, otra palabra recorrerá ahora las nuevas poéticas: normalidad. Lejos queda aquel Manifiesto subnormal que Manuel Vázquez Montalbán publicara en 1970. A una España supuestamente normalizada ya en su democracia, respondía una literatura también normal, alejada de la de aquellos libros que perdían la mitad de sus palabras en cuanto se agitaban ligeramente en el aire, como sostenía Luis García Montero, el poeta de la experiencia que más ha cuestionado la lección de las vanguardias y que más se ha significado en este nuevo escenario. La democracia supuso para muchos de los nuevos poetas en

17. En el prólogo a Leopoldo María Panero, Agujero llamado Nevermore (Selección poética, 1968-1992).

18. Leopoldo María Panero, «La metamorfosis» (2014: 363). De El castillo dirá también que es el «único relato fidedigno de una sociedad paranoica» (Leopoldo María Panero, «La psiquiatría o el castigo de la extrańeza», 2014: 456. 
cierto modo un regreso a casa, una vuelta al orden. «Más que quemar los libros, quiero volver a ordenar nuestra biblioteca», afirmaba también García Montero para cerrar su texto "El oficio como ética», en frase que se ha hecho célebre (García Montero, 2003: 68).

No es momento ahora de entrar con más profundidad en los planteamientos teóricos de la poesía de la experiencia, que siguen siendo objeto de controversia en el campo literario espańol. Lo que me interesa subrayar es que la escritura radical, vanguardista de los setenta, pasa a ser para las nuevas voces de los ochenta prácticamente la excepción en una supuesta historia, natural y realista, de la literatura espańola. Esta toma de postura a la contra de las rupturas anteriores permite entender la vehemencia y virulencia con que nació en 1996 el colectivo valenciano, poético y político, Alicia Bajo Cero, «(im)propio nombre [...], significante giratorio que anticipa la inminencia del estigma», como escribía y anticipaba Antonio Méndez Rubio, uno de sus principales integrantes (2008: 177). Alicia Bajo Cero denunció, entre otras cosas, lo que entendió como nuevo consenso acrítico entre lenguaje y mundo por parte de la poesía de la experiencia y, en este sentido, convergió con las denuncias de otros colectivos afines como Unión de Escritores del País Valenciano, el Movimiento de Objeción de Conciencia, las Madres de Mayo o Valencia acoge. Desde algunos de sus manifiestos puede leerse otra vez una apuesta por una poesía que sea capaz de agujerear la montaña y salir del otro lado, como se defendían al inicio de Mil mesetas de Deleuze y Guattari (en Méndez Rubio 2008: 177) ${ }^{19}$. Alicia estaba ahí de nuevo para animar a atravesar el espejo y para recordar, irónicamente, el país de las maravillas que volvía a ser la España del momento.

Antes de la aparición de Alicia Bajo Cero, la dramaturga Angélica González, otra española que ha acabado huyendo de Spanndereta, se cambiaba su apellido y pasaba a ser Angélica Liddell. Otra vez Alicia estaba ahí para demostrar que las cosas no son como parecen, mucho menos como se dicen con el lenguaje, que no hay manera de evadirse de lo irrepresentable, que ese no-hay-manera parece ser la única posibilidad de vivir. Y en este aspecto, su sacrificio como acto poético (así se titula uno de sus principales textos ensayísticos) es una oposición al sentido común, establecido, empoderado, y enlaza directamente con Panero, con Artaud, con Pasolini, con Bataille, con todos aquellos que hablaron de lo que nos hace iguales sin igualarnos, es decir, de la pasión (Liddell 2014: 118). Hay aquí un pathos compartido.

Toda poesía no adscrita a la "poesía de la experiencia» en las últimas décadas en España se ha adentrado en el agujero de Alicia y, en este sentido, ha seguido cuestionando la hegemonía de lo obvio y convenido, no para contra-poner otro orden de cosas, sino para disolver la dialéctica con que el propio poder funciona. En este aspecto, todas estas últimas poéticas enlazan con aquellas otras de los setenta, encarnadas en los poetas que, como Leopoldo María

19. Ver sobre todo: Alicia Bajo Cero, Poesía y poder, 1996. Disponible en: http://myslide.es/ documents/poesia-y-poder-116-pgs.html. 
Panero, entre otros muchos, necesitaron sacar de sus casillas a las palabras y liberarlas de la falta de lógica de la lógica que las ha situado ahí, de una razón que, irracionalmente, no acaba de mover ficha.

\section{Bibliografía}

Alicia Bajo Cero, Poesía y poder, Valencia, Ediciones Bajo Cero, 1996.

Artaud Antonin, Carta a la vidente, Barcelona, Tusquets, 1971.

- El teatro y su doble, Barcelona, Edhasa, 2011.

Blesa Túa, Leopoldo María Panero. El último poeta, Madrid, Valdemar, 1995.

Bozal Valeriano, El tiempo del estupor, Madrid, Siruela, 2004.

Buckley R., La doble transición, Madrid, Siglo XXI, 1996.

Carroll Lewis, Alicia en el Pais de las Maravillas, prólogo, edición y traducción de Jaime de Ojeda, Madrid, Alianza Editorial, 1970.

- El juego de la lógica y otros escritos, selección, traducción y prólogo de Alfredo Deaño, Madrid, Alianza Editorial, 1972.

- Alicia al otro lado del espejo, prólogo, edición y traducción de Jaime de Ojeda, Madrid, Alianza Editorial, 1973.

- Matemática demente, prólogo, edición y traducción de Leopoldo María Panero, Barcelona, Tusquets, 1975.

Chacel Rosa / Moix Ana María, De mar a mar, prólogo, edición y notas, Barcelona, Península, 1998.

Deleuze Gilles, Lógica del sentido, prólogo de Miguel Morey, Barcelona, Paidós, 1989.

Eagleton Terry, Terror sagrado. La cultura del terror en la historia, Madrid, Editorial Complutense, 2007.

Foucault Michel, Las palabras y las cosas, Madrid, Siglo XXI, 2010.

García Montero Luis, «El oficio como ética», en La casa del jacobino, Madrid, Hiperión, 2003.

Goytisolo Juan, «Más vale pájaro suelto», El País, 8 de abril de 2006 (disponible en http://elpais.com/diario/2006/04/08/babelia/1144453825_850215.html)

Holloway John, Cambiar el mundo sin tomar el poder. El significado de la revolución hoy, Barcelona, Ediciones de Intervención Cultural, 2002.

Liddell Angélica, El sacrificio como acto poético, Madrid, Continta Me Tienes, 2014.

Méndez Rubio Antonio, La destrucción de la forma (Y otros escritos sobre poesía y conflicto), Madrid, Biblioteca Nueva, 2008.

Morey Miguel, Lectura de Foucault, Madrid, Sexto Piso, 2014.

Panero Leopoldo María, Agujero llamado Nevermore (Selección poética, 1968-1992), ed. Jenaro Talens, Madrid, Cátedra, 1992.

- Poesía completa, 1970-2000, ed. Túa Blesa, Madrid, Visor, 2004.

- Traducciones / Perversiones, ed. Túa Blesa, Madrid, Visor, 2011.

- Prosas encontradas, ed. Fernando Antón, Madrid, Visor, 2014.

Praga Inés, «Alicia (in)cumple 150 años», Hypérbole, 11 de agosto de 2015 (disponible en: http://hyperbole.es/2015/08/alicia-incumple-150-anos/)

Ríos Julián, Álbum de Babel, Barcelona, Muchnik Editores, 1995. 
